\title{
Dr. Lautaro Rodríguez López (1943 - 2006)
}

Walter Avdaloff V.

Instituto de Diagnóstico cerebral

$\mathrm{N}$ ació en Ovalle el 9 Diciembre 1943. Falleció en Santiago el 23 de Febrero 2006.

El Dr. Lautaro Rodríguez fue un hombre y un médico de múltiples méritos.

Neurocirujano de gran habilidad, fue el fundador, desde la nada, del Servicio de Neurología y Neurocirugía del Hospital San Borja Arriaran en 1990.

Durante los 16 años que fue su Jefe de Servicio, tuvo un brillante desempeño, con gran creatividad.

Heredó de sus maestros del Instituto de Neurocirugía, en especial del Dr. Alfonso Asenjo, una gran capacidad administrativa y organizacional. Muy proactivo, llevó a que el Servicio incipiente de Neurocirugía, el cual contaba solamente con su persona inicialmente, creciese fuertemente. En efecto, con su generosidad aportó miles de dólares en material e instrumental de primera calidad, que había traído de Venezuela y de USA, entregándolo al Hospital, donde se pudo implementar una neurocirugía de alta complejidad, con más de 6.000 pacientes operados en su período.

Fue además un creador de equipos de trabajo: rápidamente incorporó a un gran número de neurocirujanos que incrementaron el Servicio, muchos de los cuales son sus discípulos o colaboradores exitosos. Algunos estudiantes de M edicina fueron fascinados por su trabajo, motivándolos a la especialidad de neurocirujanos, como fue el caso de la Dra. Claudia Villablanca, entre otros. Recibió además un variado y talentoso grupo de médicos extranjeros para su formación.

Otro aspecto que lo retrata en su generosidad

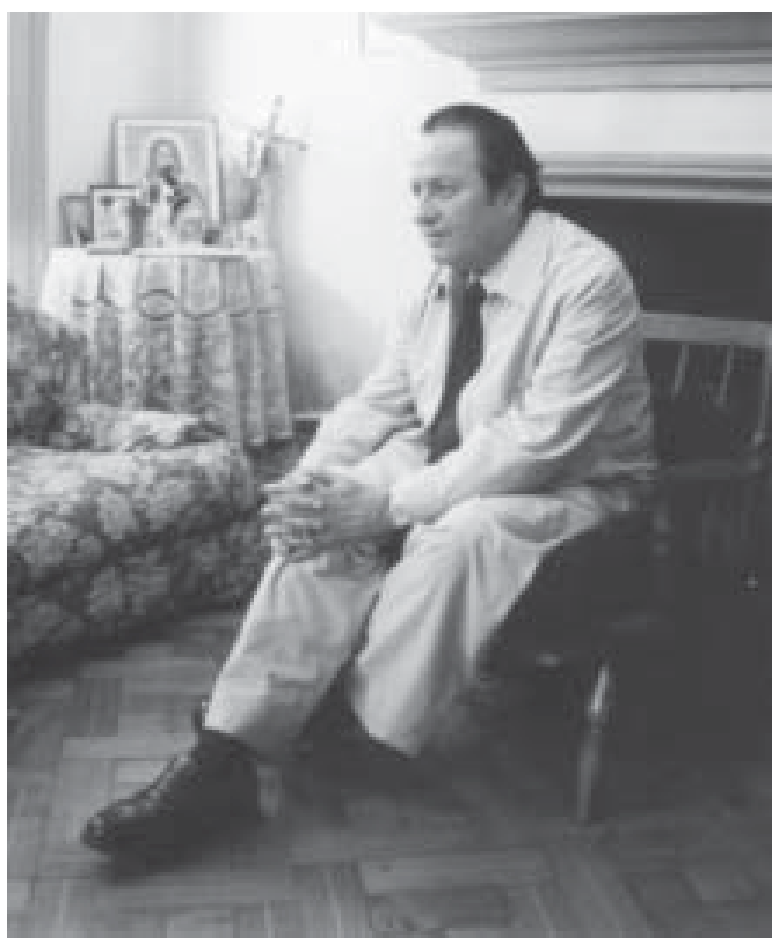

fue la entrega de conocimientos, literatura, material de estudio e incluso ayuda económica, a los médicos recién llegados a Chile, seguramente producto de la sensibilidad de haber vivido por muchos años en Venezuela.

Fue un gran docente con un enorme cariño por la Universidad de Chile.

Tan pronto se instaló en el Hospital, inició contactos y docencia ad honorem con la Universidad, hasta que en 1995 fundo el Departamento de Neurología de la Universidad de Chile área Centro. Desde esa época fue el Director del Departamento, dedicado a la docencia de Pregrado, con gran éxito y aprecio por los alumnos.

Fue además un hombre multifacético, nació en Ovalle, se educó en el Instituto Barros Arana en Santiago y en la Facultad de Medicina de la Universidad de Chile.

Fue un excelente alumno con una memoria privilegiada, muy rápido y práctico, lo cual presagiaba sus éxitos como neurocirujano. Se formó 
en el instituto de Neurocirugía, siendo de los últimos alumnos del Prof. Asenjo y de su gran maestro Héctor Valladares. De ellos heredó un sentido organizativo y proactivo así como técnicas neuroquirúrgicas muy depuradas.

El afán de investigador y de experimentar hizo que muy precozmente se interesara en la Neurocirugía pediátrica, en desarrollar y aplicar procedimientos de doppler transcraneano y técnicas de ultrasonido intraoperatorio.

La crisis que vivió nuestro país, hizo que su maestro Dr. Héctor Valladares se exiliara en 1973, decidiéndose a seguir los mismos pasos y auto exiliarse en Venezuela en 1974. Vivió en Venezuela en la ciudad de M érida, donde fundo el Servicio de Neurocirugía y fue profesor de la Universidad de los Andes de M érida.

Cultivaba la historia de la medicina y de las ciencias neurológicas, con múltiples referencias y anécdotas de los personajes, lo cual lo hacia muy entretenido y traía con gran riqueza a la realidad a personajes pioneros en nuestra especialidad en Chile.

Dentro de sus múltiples intereses, los cuales siempre deparaban sorpresas, estaba el ser un gran aficionado y coleccionista de objetos circenses, conocedor de la historia del circo, del box y del fútbol.

Finalmente, aquello que lo caracterizaba era su gran capacidad de trabajo, la rapidez, la lealtad y generosidad. Poseía un carácter firme y decidido y creativo. Fue uno de los últimos profesores y neurocirujanos herederos directos del estilo de la gran escuela de la N eurocirugía del Instituto de los años 70.

Los sobreviven su mujer y dos hijos. 